\title{
Elderly Using Computer Tools for Learning about Aging
}

\author{
Anderson Jackle Ferreira1, Denise Goulart1', Juan José Mouriño Mosquera², \\ Claus Dieter Stobäus ${ }^{3}$ \\ ${ }^{1}$ Postgraduate Program in Education, Pontifical Catholic University of Rio Grande do Sul-PUCRS, \\ Porto Alegre, Brazil \\ ${ }^{2}$ Postgraduate Program in Education, Pro-Rectory of Postgraduate and Research, Pontifical Catholic University \\ of Rio Grande do Sul, Porto Alegre, Brazil \\ ${ }^{3}$ Postgraduate Programs in Education and in Biomedical Gerontology, Pontifical Catholic University of \\ Rio Grande do Sul-PUCRS, Porto Alegre, Brazil \\ Email: stobaus@pucrs.br
}

Received 20 April 2016; accepted 31 July 2016; published 3 August 2016

Copyright (C) 2016 by authors and Scientific Research Publishing Inc.

This work is licensed under the Creative Commons Attribution International License (CC BY).

http://creativecommons.org/licenses/by/4.0/

(c) (i) Open Access

\begin{abstract}
The article is the result of a collaborative group text, after discussion between the authors, based on the debate about their produced texts, further information from developed Capability Project: Digital Inclusion Workshop, developed at the Institute of Geriatrics and Gerontology at PUCRS, and new information collected from the Extension Courses: Education, Inclusion and Aging, at PUCRS. Through the analysis of the speeches of those seniors who participated in the workshops, we listed some possibilities for the coming years on human development, especially in late adulthood, and for the idea of a healthier and more qualified lifespan approach.
\end{abstract}

\section{Keywords}

Elderly, Educational Psychology, Gerontology, Ageing, Lifespan Approach

\section{Introduction}

Aware of computerized technological acceleration, growth in the number of elderly people, the need for change in pedagogical approach and methodologies traditionally used in initiatives aimed at the elderly, we all can note that there is increasing the area of Information and Communication Technologies, in the needs and dependence on "the modern way of life". But there is a lack of opportunity to the elderly to access to these modern technologies, so that some of them are "disconnected from the reality". So, we discuss here about the perceptions of the 
elderly participant the workshops about.

\section{Literature Review}

As we said about Lévy’s (1993), Stobäus, Ferreira, Marques, Wehemeyer, Goulart, \& Mosquera (2014: p. 136) ideas:

The Computer composes a cognitive ecology, progressively impossible to imagine, for years to come, unrelated contexts of new technological reality. This, in turn, is a set of features that influence the culture and ways of constructing knowledge of the whole society.

And Lévy (1993) also said about the utilization of Internet that have also a didactic character, and is necessary on these days, we are part of the group who developed digital inclusion for elderly, because of our relationship with the Postgraduate Course of Biomedical Gerontology and Postgraduate course on Education Faculty, at our university.

As Goulart, Jackle, Mosquera, \& Stobäus (2015: p. 961):

When the digital inclusion project for seniors, conducted by the Institute of Geriatrics and Gerontology at PUCRS, began operations in 2003, its first class had 15 seniors. That year, the interest of late adults in a digital inclusion workshop was more directed to the practice of a group recreational activity than in their own Intellectual curiosity and desire for new learning. For those students initially Informatics was just another one of the forms of hobby and fun.

In the beginning, the Digital Inclusion Workshops were aimed at (p. 962):

[...] The pursuit of knowledge about aging, providing them to perform self-worth, with putting into practice their intellectual curiosity and improvements in its bonding, and contact and deepening in research activities and the use of resources technology [...]. They were taught by students and alumni of the Graduate Program in Biomedical Gerontology, in two-hour weekly meetings with four classes with 20 seniors each.

Later, in 2000, we decided to continue with the workshops, offered at the level of Extension Education, Inclusion and Aging, 6 editions, until 2015.

Currently, they are called Extension Course: Education, Inclusion and Aging and is in its 7th edition.

Mosquera \& Stobäus (2006: p. 105) point out that:

[...] The human being is in need of positive valuation or self-esteem and this is learned through internalization, introjection of recovery experiments performed by others in social interaction.

In our work with these elderly in inclusion, not only appears digital inclusion, but they also point out that had greater access to family and social inclusion. And it will also decrease earlier stereotypical ideas about "cannot learn", "at this age is difficult to change things", "I'm ready", among others. In fact, they have more versatility in the first most basic management of the Internet and the use of tools, in time added more possibility of individualization by not so great dependence everyone others in the use of technologies as well as increase of curiosity and for some, recovery of creative processes, particularly in terms of visual arts. Moreover, committing the possibilities of (re)visits to historical mementos lived in earlier times, the possibilities of online queries.

Later, in 2012, we decided to continue with the workshops, offering level of Extension Education, Inclusion and Aging, now with 6 editions until 2015.

Also according to Goulart, Jackle, Mosquera, \& Stobäus (2015: p. 961):

According to their reports and observations in accompanied groups, the greatest incentive to carry out the activities been linked to a higher expectation for the acquisition of knowledge that enabled internet browsing. When asked about the reasons that led them to have such an interest, they reported the elderly, for example: "Communication with children and grandchildren", "update", "meeting places" (travel), "understand what my grandchildren and/or children are doing", "shopping without leaving home", "talk with friends and not spend more phone", "enter sites" (television programs) and "find recipes" (gastronomy).

Santos, dos Stobäus, \& Mosquera (2005), in research with teachers on the use of Information and Communication Technologies, found que Also in young adulthood there are such suspicions about "threatening" technol- 
ogies to be afraid to use Them, because of people "digitally literate" do not understand well. Much more with elderly. Today, with the rapidly evolution in these area, the idea on "full impossibilities aging” can be evolved to a more realistic concepts and qualitatively better serious aging.

As Ferreira (2009), the elderly population is rapidly growing in the world, and Brazil's expectation of being the sixth country with the largest number of elderly people in next 20 - 30 years.

In our, and another developing countries, as we said (Stobäus, Ferreira, Marques, Wehemeyer, Goulart, \& Mosquera, 2014: p. 139):

Age, culturally, remains more linked to intellectual stagnation and this understanding of age can be found within their own conceptions of aging when seniors who end up elect this stage of life as a time of rest of his/her life and says that have no need for new learning.

Our and other authors researches point for development of specific educational projects for the elderly public, through a greater focus on their needs, interests and development itself (Stobäus \& Mosquera, 2013).

Another example was the study of Echt, Morrell, \& Park (1998), comparing two groups of 46 elderly: the first between 60 and 74 years and the second between 75 and 89 years. The intent of the survey was to collect data on the conditions of the acquisition and retention of basic skills on the use of the computer. The groups were trained on basics of computing, through interaction with a multimedia program and illustrated manual. The evaluation was made after training and was repeated after a week. As result they comment that the first group had better motor coordination, unless requested assistance and help and took less time in training. Both groups showed occasional forgetfulness on the resources of the computer and how to run them.

In the study of Goulart (2011), when questioned about their motivations to learn in adult courses, elderly answered that there they mean there are several reasons to their learning, like desire to, necessity to understand young people (children, grandchildren), to understand the world changes. Results also in improve family relationships and increases self-esteem.

Ferreira, Stobäus, Goulart \& Mosquera (2011) said about elderly fears, that, when older people begin to have contact with the computerized means, especially with the use of the Internet, a new universes presented and Prejudice and fear, which are of ten seen in their attitudes regarding the use of equipment or technologies "new", just disappear before the number of options that are presented to them.

So, in a perspective of the new Positive Psychology, we can say that there is a necessity to recognize the better elements who people have, and encourage their evolution in terms of, again, competences in knowledge, abilities and values.

It was possible to identify in the activities developed that they are indicatives to the Aging of Activity Theory (Néri, 2001), which supports the idea that active people age better, finding replacements for lost papers.

And another idea we can remark is the presence of a lot of affectivity in these extension courses, as we saw in the interpersonal relationships between elderly, and with us as teachers, as we researched in another contexts (Dohms, da Conceição Lettnin, Mendes, Mosquera, \& Stobäus, 2014).

\section{Methodology}

We use qualitative methods to evaluate the data obtained in the narratives at our classes, in chat encounters, with the elderly, in the seven extension courses we developed until 2015.

Using the Content Analysis Method, as proposed by Bardin (2012), we obtained categories, in its three stages (detection of themes, categorization, analysis and inference), we obtained categories, as explained next.

In all the initial meetings courses were more used to guide the elderly on the larger goals of the course, use of materials, computer management and its main digital tools toward how they would position themselves, conduct in-person and distance interactions, with teachers and their "colleagues", using the Internet. The development of the course takes into account readings and discussions on the broad theme of aging, divided into four main modules, with materials and subsequent discussions: 1. Characteristics of human aging; 2. Aging theories; 3. The inclusion of the elderly in social and cultural contexts of today; 4 . Education and aging.

The courses were offered to the university community, and the participants were professionals in the areas of health and education and other stakeholders in these fields (general public), 102 students at all of the seven courses. Of these, 79 were female and 23 male, from 39 cities from 12 Brazilian States and one from Europe 
(Portugal):

1st edition of 10.29.2012 to 11.25.2012-Total participants: 18

2nd edition of 06.05.2013 to 06.02.2013-Total participants: 18

3rd edition of 11.18.2013 to 12.22.2013-Total participants: 18

4th edition of 26.05.2014 to 29.06.2014-Total participants: 14

5th edition of 09.08.2014 to 12.10.2014-Total participants: 20

6th edition of 05.04.2015 to 06.21.2015-Total participants: 08

7th edition of 11.16.2015 to 03.01.2016-Total participants: 06

In all the initial meetings courses were more used to guide the elderly on the larger goals of the course, use of materials, computer management and its main digital tools toward how they would position themselves, conduct in-person and distance interactions, with teachers and their "colleagues", using the Internet.

\section{Discussion}

The development of the course takes into account readings and discussions on the broad theme of aging, divided into four main modules, with materials and subsequent discussions: 1. Characteristics of human aging; 2. Aging theories; 3 . The inclusion of the elderly in social and cultural contexts of today; 4. Education and aging.

\subsection{Beginning of the Course}

These "new contacts" also take into account the need of motivation (extrinsic) of the teachers at all times, so that the "climate" intra- and extra-class remains "off" all the time. Ito also implies a certain availability of online teaching, so try to respond as quickly as possible the questions and contacts the student asks.

As an example, one of the teachers said in the chat:

You are making your own study schedule, according to your routine, but remember, our course has mandatory activities that must be carried out within the period of each module and are prerequisites to receive the certificate of completion, as the very participation in chat/forum. Um great course and welcome to all!

Constantly appear at the end of messages encouraging teachers, with terms with "hugs". We develop these ideas in our article about affective development (Dohms, da Conceição Lettnin, Mendes, Mosquera, \& Stobäus, 2014) and about Positive Psychology (Stobäus \& Mosquera, 2014).

\subsection{Requirements for Working with the Elderly}

It is worth mentioning here that work with students, especially seniors, requires constantly working respect for differences, to establish positive interpersonal relationships from individuals who are going to knowing and recognizing each other, with different levels of self-image, self-esteem and self-concept, affective elements, among other topics directly related to Education and Inclusion. All within a line to adopt more reposition itself for positives rather than on diseases or patients (who are emus that often arise in the accounts).

Sometimes it's the very elderly that repositions like this when he says:

Regarding the Aging Theories note that historically the aging theme presented resistance in figuring as important due to fear of the disease, denial of death and finitude. Thanks to scientific advances and many other movements the subject gains notoriety mainly in the scientific and academic world and we have as a reference for studies, analyzes and to support our practices biological, sociological and psychological approaches.

As we proposed in our book (Stobäus \& Mosquera, 2013), there are elements we can use as educational tasks, for example workshops, continuing education, in service training.

\subsection{Issues Addressed Diversity}

Also, as these teachers more introductory courses let students go by itself can lead to various directions, reported below.

A student, from the theme aging on the texts, reading on the Activity Theory says: "because I believe it is important to encourage the elderly so that it can, as long as possible, develop their autonomous activities". 
When sought information on longevity, says when chatting "Oh? and a curiosity: Jeanne Louise Calment, a French, was the person who most lived up to the world today, 122 years!”

Some reflect more deeply like this on the aging theories, "such information is relevant and are designed to all those who care about the promotion and inclusion of our elderly in a more equal world. Thus my perception has become more sensitive and keen to observe the elderly".

Another way to see the impact you can access the new know ledges and its application in reality is this speech: "in my reality, in my workplace, I will accompany groups of elderly people, which motivated me to seek better understand this population".

Or like this other, "the reading of the two theories by observation and believe that the aging of the quality will depend very much on the person's lifestyle, passing by to social dietary factors".

And there are people who can join the "reality daily readings" through critical reflection: "we are studying this course, we saw that the preservation of autonomy and independence contributes to active aging, removing or delaying dementia cases. All routine activities or new learning are recommended for healthy aging and happy”.

Or as another said, "it is noteworthy that it goes beyond the work the body aimed at strengthening the joints and muscle tone gain, thus favoring the dynamic and static balance, major problems of the elderly, since the lack of those lead them to fall However, higher gain, I think, is in rehabilitation, in raising self-esteem, the restructuring of self-concept and self-image, causing profound changes, giving them more security, confidence and independence”.

Even when the lines go in the direction of cultural counterpoints with this speech: "I think we can inspire us, but frieze that only inspiration in societies such as Japan, that are very different cultures, and try to create a space that is a space within the own culture for young and old where interaction is interesting for both and the social as a whole".

In order to better and more productive interpersonal relationships, this speech coincides with the theme of intergenerationality: "but it is also essential to establish spaces for the exchange of perceptions among the young and the elderly, giving opportunity for the approach and interaction of individuals with experience and experiences so peculiar. The approach allows the knowledge and encourages respect for others".

Can be supplemented by these two other lines: "the strict point of view of this relationship, I also think that the creation of spaces/activities that promote interaction between the young and the elderly can contribute to closer ties between them"; and "when individuals age with autonomy and independence, the difficulties are alleviated and thus save the investments of both the family and society, but this view is a construction that must happen since childhood, encouraging the elderly, so that they feel useful and not as a burden, both in the family and in society in order that relations between generations are not disadvantaged and our seniors can live in harmony and harmony in a technological era of such rapid and intense change”.

When the theme Education and Aging was approached, one of them said: "chapter that deals with the education for digital inclusion for older people seemed to me significant. A lot of opportunities open up, bringing (the elderly) self-esteem, sense of freedom, consultation/research and communication”.

More directly to the course, speaks that: "digital education, focused on information and communication technologies (ICTs), develops factors such as cooperation and autonomy which, if worked in an integrated way, awakens in the elderly the desire to learn from this form of learning, allowing them a greater questioning of the facts, because individuals can exchange their varied experiences throughout their lives".

In order to go further study, he said one of them, "this text fascinated me and I am already thinking of organizing a workshop in educational gerontology reading and textual production for the elderly".

Another said: "need to construct a gerontological education geared to generate knowledge to the understanding of what it means to grow old in order to offer motivating, productive and also more supportive interpersonal relationships throughout life”.

We are (Ferreira, Stobäus, Goulart, \& Mosquera, 2012) agree with this idea, in a sence that a gerontological education can be developed, also in previous steps of life, as in the fundamental education, so that we are prepared to the human evolution.

\subsection{Closing of the Modules}

In closing the module, one said: "I would like to end my contributions, leaving a final sentence for reflection: 
'we are not young. We are young'. Perhaps if we look at the aging issue in this way, we can have more sensitivity to work with her".

It followed another way: "the digital inclusion process provides members of senior recovery of self-esteem, citizenship, social interaction with the culture and leisure. In addition to the digital inclusion as a social instrument qualification of these people, it also improves quality of life and encourages the brain activity of the elderly".

Perhaps a deep thought is this: "after reading seemed that ages better who does not care much about old age, healthy aging is not connected only to health but also the psychological relationship that any person has with it if it worry too much and think that getting older is a problem, the chances of that old age is a problem will be much greater".

In a more educational direction, this speech is well positioned, "thus Educational Projects with a focus on digital and social inclusion are fundamental in a country that gets old quickly and haphazardly, because they can minimize the contemporary social problems. Therefore educational initiatives focused on elderly need to be generated in the process of building an educational intervention and gradual and continuous process evaluation throughout its development, to recognize the needs and desires of the elderly".

As there are in an extension course, they believe it is possible to expand its potential for all his life, seeking more quality, that education can certainly contribute.

\section{Conclusion}

We can say, at these moments, that computers are acquiring greater importance in the daily life, and we contribute to the reduction in the number of elderly at these time considered by the others and themselves as excluded from the computerized context.

\section{References}

Bardin, L. (2012). Análise de conteúdo [Content Analysis] (3rd ed.). Lisboa: Edições 70.

Dohms, K. P., da Conceição Lettnin, C., Mendes, A. R., Mosquera, J. J. M., \& Stobäus, C. D. (2014). Affectivity of University Teachers: Personal, Social and Institutional Aspects. Psychology, 5, 1783-1793. http://dx.doi.org/10.4236/psych.2014.515185

Echt, K. V., Morrell, R. W., \& Park, D. C. (1998). Effects of Age and Training Formats on Basic Computer Skill Acquisition in Older Adults. Educational Gerontology, 24, 3-25. https://www.learntechlib.org/p/84497/ http://dx.doi.org/10.1080/0360127980240101

Ferreira, A. J. (2009). Concepção de envelhecimento de idosos autores de materiais instrucionais:Análise de texto e imagem [Concepts of Aging of Elderly Authors of Instructional Materials: Text and Image Analysis]. Tese (Doutorado Gerontologia Biomédica)-PUCRS, Porto Alegre.

Ferreira, A. J., Stobäus, C. D., Goulart, D., \& Mosquera, J. J. M. (2012). Educação \& Envelhecimento [Education \& Aging]. Porto Alegre: EdiPUCRS. E-book [Recurso Eletrônico]. http://ebooks.pucrs.br/edipucrs/educacaoeenvelhecimento.pdf

Goulart, D. (2011). Aprendizagem sem erro em idosos nas oficinas de inclusão digital. Porto Alegre: PUCRS, Tese (Doutorado Gerontologia Biomédica)-PUCRS, Porto Alegre. http://repositorio.pucrs.br/dspace/handle/10923/3602

Goulart, D., Jackle, A. F., Mosquera, J. J. M., \& Stobäus, C. D. (2015). Efeitos de Oficinas de Inclusão Digital em adultos tardios: Novos conhecimentos para um envelhecimento saudável [Digital Inclusion Workshops Effects in Late Adults: New Knowledge for Healthy Aging]. Estudos Interdisciplinaressobre Envelhecimento, 20, 959-973.

http://www.seer.ufrgs.br/RevEnvelhecer/article/view/20998

Lévy, P. (1993). As tecnologias da inteligência [The Intelligence Technologies]. São Paulo: Ed34.

Mosquera, J. J. M., \& Stobäus, C. D. (2006). Auto-imagem, auto-estima e auto-realização na universidade. In D. Enricone (Org.). A docência na educação superior: Sete olhares. Porto Alegre: EdiPUCRS.

Néri, A. L. (2001). Desenvolvimento e envelhecimento: Perspectivas biológicas, psicológicas e sociológicas [Development and Aging: Biological, Psychological and Sociological Perspectives]. Campinas: Papirus.

Santos, B. S., dos Stobäus, C. D., \& Mosquera, J. J. M. (2005). O mal-estar docente perante o uso das tecnologias de informação e comunicação [The Teacher Malaise against the Use of Information and Communication Technologies]. Revista Electrónica Iberoamericana sobre Calidad, Eficacia y Cambio en Educación, 3, 344-358.

Stobäus, C. D., \& Mosquera, J. J. M. (2013). Educação e Inclusão: Perspectivas desafiadoras [Education and Full Inclusion: Challenging Perspectives]. Porto Alegre: EdiPUCRS. 
Stobäus, C.D., \& Mosquera, J. J. M. (2014). Positive Psychology and Emotional Schedule: Building Healthy Self-Construction. Psychology, 5, 533-540. http://www.scirp.org/journal/PaperInformation.aspx?PaperID=45269 http://dx.doi.org/10.4236/psych.2014.56063

Stobäus, C. D., Ferreira, A. J., Marques, C. P., Wehemeyer, C. de O. T., Goulart, D., \& Mosquera, J. J. M. (2014). Elderly Answer about Concepts of Aging and Computer Use: Educational Psychology and Gerontological Perspective. In C. Pracana. In PACT-Proceedings. Porto-PT, 2014, 135-139.

\section{Submit or recommend next manuscript to SCIRP and we will provide best service for you:}

Accepting pre-submission inquiries through Email, Facebook, LinkedIn, Twitter, etc.

A wide selection of journals (inclusive of 9 subjects, more than 200 journals)

Providing 24-hour high-quality service

User-friendly online submission system

Fair and swift peer-review system

Efficient typesetting and proofreading procedure

Display of the result of downloads and visits, as well as the number of cited articles

Maximum dissemination of your research work

Submit your manuscript at: http://papersubmission.scirp.org/ 